\title{
El discurso de Ricardo Palma en el III Congreso Americano de Estudiantes de 1912
}

Por Manuel Pantigoso Pecero 
Poeta, crítico literario y de arte, dramaturgo y maestro universitario, promotor cultural y periodista. Doctor en Literatura y Filología y doctor en Educación. Profesor Emérito de la UNMSM. Director de la Oficina Central de Extensión Cultural y Proyección Social de la U.R.P. 
Como introducción el autor se refiere a los acontecimientos que llevaron a la renuncia de Palma a la Biblioteca Nacional. A continuación aparece la polémica con González Prada y las veladas de desagravio por parte de la juventud. Luego, el autor inserta integramente el discurso que dio Palma en el III Congreso Americano de Estudiantes para luego, en la última parte, dar a conocer la obra intelectual y literaria de los personajes extranjeros citados por el tradicionista. Finaliza con un conjunto de conclusiones pertinentes.

Palabras claves: Biblioteca, polémica, desagravio, juventud, comunicación epistolar.

En 1912, año de la renuncia de Ricardo Palma a la Biblioteca Nacional, el Perú estaba gobernado por Augusto B. Leguía. La coyuntura era el proceso electoral que debía elegir al nuevo presidente. Habían dos candidatos: Antero Aspíllaga, del Partido Civil, que apoyaba al gobierno, y Guillermo Billinghurst, de la oposición. Llevado a cabo el sufragio, el segundo pidió la nulidad del proceso, tachándolo por haber sido organizado al servicio de los intereses del Partido Civil gubernamental. Sería el Congreso el que, luego de una prórroga de varios meses, eligió como Presidente Constitucional a Billinghurst, el 24 de septiembre de 1914. Por primera vez la masa irrumpiría en el 
escenario político; como ejemplo están las sucesivas huelgas de tranviarios, textiles y universitarios. ${ }^{1}$ Es pertinente recordar que en 1911 Jorge Chávez moriría luego de haber sobrevolado los Alpes; de igual forma, por entonces se realizarían en el Perú las primeras exhibiciones de vuelo en avión de Juan Bielovucic y Carlos Tenaud. De otro lado, José María Eguren publicaría Simbólicas, libro fundador de la poesía contemporánea en el Perú. En 1912 se publicaron libros como La creación de un continente y Démocraties Latines de l'Amérique de Francisco García Calderón, y Jardín cerrado de José Gálvez Barrenechea. También en ese año se fundaría el diario "La Crónica"; por su parte, José de la Riva Agüero viajaría al sur del país y ese periplo le servirá para escribir las vibrantes páginas de sus Paisajes Peruanos. Para Palma serían momentos de desazón y amargura por la forma cómo el gobierno manejó el asunto de su renuncia a la Biblioteca Nacional, de la que era director desde el año 1883. Sin embargo, este hecho lamentable probaría el cariño y la simpatía de los limeños, en veladas de desagravio hacia su persona y su obra.

La historia de la renuncia anunciada tendría su origen en los ácidos comentarios políticos de Clemente Palma -hijo del tradicionista- que semanalmente escribía en la revista "Variedades"2 - de la que era fundador y director-, todos ellos adversos a la política de Leguía. En su acostumbrada columna titulada "De jueves a jueves" ponía el dedo en la llaga para advertir algún acto de corrupción. Por ejemplo, en el número 210 (9 de marzo de 1912) el editorialista escribe lo siguiente:

\footnotetext{
I El primer paro estudiantil registrado en Lima ocurrió en julio de 1912, junto con el inicio del III Congreso Americano de Estudiantes.

2 "Variedades" fue fundada el 29 de febrero de 1908 y se mantuvo hasta el 27 de agosto de 1930, para entrar luego en un dramático receso y volver a aparecer entre el 18 de marzo y el 30 de septiembre de 1931, completando en total mil doscientos treinta números.
} 
Decididamente esto va hundiéndose y desorganizándose cada vez más: ya ni el ejército, esto es, lo que constituye el puntal más fuerte del régimen y sobre el que en buena cuenta reposan las audacias más inverosímiles que hemos estado presenciando, ni el ejército se ha librado de infectarse los pulmones con la respiración del ambiente corrompido, cual jamás lo fuera, en que hoy vivimos.

Clemente Palma desempeñaba la función de Conservador de la Biblioteca Nacional, cargo iniciado desde su regreso de Barcelona en 1905, donde estuvo al frente del Consulado del Perú. Al presidente de la República le caían como azotes los artículos del joven periodista y entre bastidores expidió un decreto destituyéndolo de su cargo y colocando en su reemplazo al poeta arequipeño Percy Gibson. Ello ocurriría el 13 de febrero. Ricardo Palma, apelando al reglamento de la Biblioteca vigente desde 1884, que daba al Director la prerrogativa de proponer a sus empleados, envió una enérgica carta (15 de febrero) al encargado del Ministerio de Instrucción Pública Justo Pérez Figuerola en cuyo alegato señalaba lo siguiente:

Aceptar la imposición de un Conservador, cuya persona, ilustración y competencia bibliográfica me son desconocidas, renunciando al derecho que el reglamento me acuerda, es tan injustificado como desdoroso para la dignidad de mi nombre, sobre todo tratándose del reemplazo de un empleado que no ha incurrido en falta en el desempeño de su puesto.

Sírvase, pues, Ud. dar por presentada mi renuncia del cargo de Director de la Biblioteca ${ }^{3}$.

3 Luis Alberto Sánchez. Manuel González Prada, Tomo II, Volumen 3, p. 405. 
La renuncia no sería aceptada pues el gobierno estaba "ampliamente satisfecho" de sus servicios como Director de la Biblioteca, por lo que el 22 de febrero Palma contesta que "como la no aceptación de mi renuncia implica el reconocimiento de mi derecho para proponer empleados en las vacantes que ocurrieren (...) próximamente pasaré al Ministerio una propuesta en favor de la persona que, por constarme sus aptitudes e ilustración, deba reemplazar al Conservador, doctor Clemente Palma, en el empleo que hasta ayer estuvo en posesión".

Palma tenía en mente colocar como sustituto de su hijo al poeta Alberto Ureta. Pero vino lo más grave. El Ministerio derogó el reglamento que daba al Director la prerrogativa de escoger a los empleados y dictó un decreto reformatorio del mismo para mantener el nombramiento a favor de Percy Gibson. Este hecho hirió la dignidad del tradicionista quien en carta del 1 de marzo insistió en su renuncia por "no estar ya el Supremo Gobierno ampliamente satisfecho de mis aptitudes y merecimientos", palabras que acentuaba para enrostrar las contradicciones que entrañaban el atropello. El Gobierno, en segunda nota del 4 de marzo, no aceptó la renuncia, a lo que Palma respondió como la egregia figura que siente mancillada su dignidad y su labor de años. Con viril énfasis expresó lo siguiente:

Si el Supremo Gobierno insiste en declarar que está ampliamente satisfecho de mis servicios y al mismo tiempo me retira la facultad de proponer a los empleados de esta oficina, incurre en una burla a mis canas, a los cuarenta y cinco años de servicios prestados al Estado, a la poca o mucha reputación que me he conquistado con mi perseverante labor y a mi dignidad de jefe de una oficina que me debe su existencia, burla a la que no me puedo resignar. En tal virtud ruego a usted que tenga a bien transmitir al Supremo Gobierno mi insistencia en la renuncia. 
Ante estas palabras expresadas con decoro y dignidad el Gobierno resolvió el 6 de marzo aceptar dicha renuncia, pero a la vez decidió nombrar para reemplazarlo a Manuel González Prada, "quien deberá recibir en el día y bajo inventario cuanto contiene el mencionado establecimiento".La incorporación de González Prada a la Biblioteca reavivó viejas rencillas y ese conato intelectual con el autor de las Tradiciones.

Una vez consumado el atropello gubernamental la sociedad limeña en su conjunto le expresaría a Palma su solidaridad en una multitudinaria velada de desagravio. Los diarios de la capital y de provincias, así como la prensa internacional, se ocuparon del escandaloso incidente, reprobando la arbitrariedad del gobierno de Leguía y enalteciendo la honra del gran tradicionista. Esta velada de desagravio se realizó en marzo, a pocos días de su salida de la Biblioteca. El lugar escogido fue el Teatro Municipal. Tomaron la palabra José de la Riva Agüero, Juan Bautista de Lavalle, Felipe Barreda y Laos, Felipe Sassone y José Gálvez Barrenechea, quien leyó un texto lírico de homenaje al maestro. Esta pública manifestación de simpatía se recoge en las crónicas de la época y en los propios escritos del tradicionista. Por su lado, César Miró en Los Oficios de don Ricardo (pp. 166-167) recordaría lo sucedido:

La respuesta a esa medida del gobierno es multitudinaria y se traduce en una pública demostración de desagravio. Ya no es la coronación propuesta en repetidas ocasiones y otras tantas rechazadas por el escritor. El homenaje tiene esta vez otro significado. Se ha elegido para realizarlo el Teatro Municipal. Desde el día anterior se recomienda a los periódicos comunicar a las personas que no puedan asistir, devolver las localidades para atender la creciente demanda. La compañía de tranvías ofrecerá un servicio extraordinario a los lugares distantes después de la velada. "Nunca presentó nuestro primer teatro tan brillante aspecto", dice 
"La Prensa". No había asientos disponibles "y en la cazuela, abigarrada, henchida de entusiasmo, lo mejor de la juventud demostró con su presencia y más tarde con su alabanza atronadora, la admiración que siente por el patriarca de nuestra literatura.

Por su parte, Palma señalaría lo siguiente: "Confieso que alguna desazón me produjo, en los tres primeros días, el injustificable agravio del gobernante de mi patria; pero tornóse pronto en satisfacción y contento ante las manifestaciones de simpatía social y de reprobación al procedimiento de los hombres de palacio". ${ }^{4}$ Luis Alberto Sánchez tiene una opinión, con trasfondo político-social, de la velada organizada a Palma. Leamos:

Los "arielistas" universitarios organizaron una función de homenaje a Palma, función que era, en realidad, un ataque a Leguía, la presentación del neocivilismo intelectual y un rechazo a González Prada. Intervinieron en ella Riva Agüero, Gálvez, Sassone, Barreda y Laos, Lavalle. En realidad, aquella noche se ideó el partido Nacional Democrático, cuya declaración de principios aparecería en los primeros días de 1915. González Prada hizo la crítica de este; los editores de "Documenta", donde se recogen todos los materiales sobre Riva Agüero, la han omitido ${ }^{5}$.

En esa oportunidad Palma se mostraría profundamente agradecido, como se puede apreciar en su vibrante discurso:

Es idea corriente que los viejos, por el natural desgaste nervioso y sentimental producido en la marcha de su vida, son cerrados para las grandes emociones de dolor o de

4 Ob. cit, p. 404.

5 Luis Alberto Sánchez. La Literatura Peruana, Tomo IV, p. 1505. 
placer, de gratitud o de resentimiento; pero yo os aseguro, jóvenes amigos míos, que esta hermosa demostración de simpatía a mis canas y a mi labor con que habéis querido desagraviarme de la inmerecida actitud con que el gobierno ha respondido a mi esfuerzo de casi seis lustros en bien de la cultura de la patria, conmueve profundamente mi alma y compensa con creces las amarguras de la decepción ... Recibid, amigos míos, el abrazo estrecho que os doy con el alma entera antes de irme al desierto a plantar de nuevo mi tienda y a soñar allí con mis conquistadores valerosos, mis virreyes caballerescos y mis tapadas limeñas, gentilmente bellas y espiritualmente decidoras.

Pero aquí no quedaría todo; apenas sería el comienzo. En verdad, esta historia-que hemos estudiado extensamente en algunos artículos dedicados a Palma ${ }^{6}$ trata sobre la inquina, de varias décadas, de Manuel González Prada contra el tradicionista y su obra. Se remonta a los años posteriores a la guerra con Chile. En los vehementes discursos pronunciados en "El Ateneo", "Politeama" y "Olimpo" el autor de Pájinas Libres atacó a la generación que había perdido la guerra del Pacífico. Su frase lapidaria: "los jóvenes a la obra, los viejos a la tumba" tenía un estilete que apuntaba al tradicionista, más aun tomando en cuenta que antes del discurso en el teatro "Politeama" había pronunciado otro en el "Olimpo" en donde el destinatario era más preciso:

Cultivamos una literatura de transición, vacilaciones, tanteos y luces crepusculares. De la poesía van desapareciendo las descoloridas imitaciones de Bécquer; pero en la prosa reina siempre la mala tradición, ese monstruo engendrado por

6 En "El Perú en las tradiciones de Palma: sentido del pasado y actualidad de la lengua” (2006) y en "Ricardo Palma 'el bibliotecario mendigo' a través de sus cartas" (2013). 
las falsificaciones agridulces de la historia y la caricatura microscópica de la novela ${ }^{7}$.

Al ingresar González Prada a la Biblioteca escribió una "nota informativa” donde da cuenta "al Supremo Gobierno sobre el estado de sus tesoros bibliográficos y ponerme a salvo de futuras responsabilidades". Lo escrito está plagado de críticas a la labor de Palma en la Biblioteca. Ese opúsculo (Lima, Imprenta de la Acción Popular, 1912) que debería tener el carácter de inventario se asemeja más al libelo y al panfleto, lo cual le resta seriedad y objetividad al contenido. El tradicionista responde a estos agravios con sus Apuntes para la historia de la Biblioteca de Lima (Lima, Empresa Tipográfica Unión, 1912). Allí testimonia su participación desde su llegada a la Biblioteca como consecuencia del ultraje bibliográfico perpetrado por los chilenos; se refiere al inicio de su loable gesta como "bibliotecario mendigo"; revela el porqué de su renuncia y, finalmente, da respuesta a cada uno de los denuestos de González Prada.

Los hechos que estamos describiendo coinciden con la inminente realización en Lima del III Congreso Americano de Estudiantes ${ }^{8}$ que tendría una importancia capital. Allí se puso en agenda temas fundamentales como la autonomía universitaria, la renovación de los métodos de enseñanza y evaluaciones, el intercambio de información y alcances científicos; también los estudios libres y la reglamentación obligatoria, la unificación de los programas universitarios americanos, la representación estudiantil con miras a la Liga de Estudiantes de América, becas y bolsas de viaje. Sin duda estos encuentros estudiantiles -donde se discutía ampliamente el rol de la universidad en la sociedad orientando la educación en un sentido americano, sin

7 Luis Alberto Sánchez. Manuel González Prada, Tomo I, Volumen 1, p. 65.

8 El primer Congreso se llevó a cabo en Montevideo en 1908. El segundo, en Buenos Aires en 1910. En esa ocasión, José Gálvez presidió la delegación peruana. 
dejar de lado la cultura europea- abrieron un ciclo importante del pensamiento que conduciría a la Reforma Universitaria de Córdoba, en 1918.

En una sesión ad hoc del Congreso se llevó a cabo el homenaje de los estudiantes universitarios de América a Ricardo Palma, el cual fue impulsado por el Centro Universitario cuyo presidente era Pedro Dulanto Monterola. ${ }^{9}$ Este homenaje se realizó en su local institucional, situado en la Avenida La Colmena. La manifestación general de simpatía se dio el 31 de julio. Hay que señalar que aprovechando la presencia de las delegaciones estudiantiles, Manuel González Prada “incurrió en la indelicadeza de remitir a todos, bajo de sobre, un ejemplar del libelo". ${ }^{10}$ Este procedimiento indecoroso reforzaría, sin embargo, la adhesión de los representantes estudiantiles. Esto se haría evidente al obsequiársele al tradicionista un álbum firmado por todos los asistentes a ese trascendente Congreso. La revista "Variedades", en el número 231 (3 de agosto de 1912) detalla la participación de los estudiantes que tomaron la palabra:

Poco después de las cinco de la tarde llegó al Centro el querido anciano llevado por la comisión que le trajo de Miraflores. Su ingreso fue saludado con una salva estruendosa de aplausos y aclamaciones. Poco después leyó el presidente del Centro, señor Dulanto, un discurso hermoso y saturado de sentimientos nobles. Raimundo Morales de La Torre, primoroso y rítmico, leyó el discurso

9 El Centro Universitario se formó en 1908. Recordemos que en 1922 Carlos Alberto Izaguirre con un grupo de jóvenes, entre ellos Carlos Oquendo de Amat, fundó el Centro Universitario Ariel, que no tiene ligazón con la institución dirigida por Dulanto. Pedro Dulanto (Chancay, 1889-Lima, 1952) fue, posteriormente, abogado y político. Llegó a ser elegido Rector de la Universidad Nacional Mayor de San Marcos, el 22 de febrero de 1951.

10 Luis Alberto Sánchez. Manuel González Prada, Tomo II, Volumen 3, p. 411. 
de entrega de la ofrenda juvenil. El presidente del Centro Universitario de Arequipa, señor Ramos y García Calderón, fue el portador de la cariñosa adhesión de la juventud del Misti. Andrés Quintana Gurt tuvo frases de cálido y grato afecto para el maestro. El delegado del Brasil, señor Barros Barreto, pronunció un discurso admirable de elegancia y de elevación de conceptos generosos sobre la obra del señor Palma. El delegado chileno, señor Gonzalo Santa Cruz, tuvo conmovedoras frases para el viejo maestro a quien desde la infancia le enseñaran a venerar y querer, en su ilustre hogar. El delegado Gómez Haedo, en nombre de la juventud uruguaya y argentina, expresó con frase culta y galana la admiración que despertaba en los dos países la obra literaria del tradicionista. El señor Crespo, delegado del Ecuador, manifestó en pulido discurso la cariñosa simpatía y veneración que don Ricardo Palma inspira en la tierra de Montalvo. Y finalmente el poeta de la juventud, Gálvez, declamó una poesía dedicada al maestro.

Como tributo y demostración de agradecimiento, Ricardo Palma leyó en esa ocasión un hermoso y emocionado discurso que es de vital importancia para sopesar la solidaridad al gran tradicionista en lo referente a su vida y a su obra, sobre los cuales solo reclamaba afecto y respeto.

\section{- II -}

Señores universitarios del Perú:

Vuestra delicada atención al arrancarme de mi modesto retiro para hacerme respirar el aura de vuestro afecto juvenil, conmueve profundamente mi alma. Y es más hermosa vuestra expresión de afecto para con el anciano tradicionista, porque habéis alcanzado a 
asociar en esta gentileza a vuestros hermanos, los jóvenes estudiantes de América Latina, juzgando con razón que, si en el orden intelectual soy vuestro abuelo, algo abuelo de ellos soy también; porque en la infancia leyeron, a guisa de cuentos, algunas de mis rancias consejas. Para ellos y para vosotros, el más férvido y agradecido abrazo de mis ochenta años de labor, de luchas, de amarguras y de triunfo. Sí, de triunfo porque es un triunfo, el más hermoso y halagador, el haber alcanzado, por la perseverancia en mi labor literaria y ciudadana, este crepúsculo de afecto y de respeto, que viene a envolver mis canas con efluvios simpáticos antes de que descienda sobre mí la noche eterna.

Con infinito, inexpresable orgullo, recibo el álbum que me ofrendáis, mis jóvenes amigos, y con el que me habéis significado vuestra solidaridad conmigo, en esta hora ingrata en que fue profanada mi obra de cerca de treinta años en pro de la cultura nacional. Habéis querido hacer testigos y aún partícipes de vuestra nobleza reparadora a vuestros hermanos de América. Este es, les habéis dicho, ese viejo escribidor de tradiciones que habéis oído narrar a los hombres de la generación que ya desaparece. Este es el rimador o poeta cuyos versos conocéis, más que por sus libros, por lectura en los periódicos.

Recibo este álbum con gratitud fervorosa. En él habéis querido dejar, con vuestras rúbricas, una palpitación simpática de veneración a mis años y de complacencia con mi labor. Esta significativa actuación de hoy vibrará constantemente en mi espíritu con todos los prestigios enardecedores de una fiesta triunfal, en la que vuestros espontáneos arranques de generosidad desplegaron los estandartes de esta América que tanto amo y a la que he consagrado mis esfuerzos de escritor. Gracias, infinitas gracias, amigos míos. Mi palabra fatigada no alcanza a expresar toda la emoción del alma por el agasajo que con tanta delicadeza ofrendáis al anciano hombre de letras.

Vosotros, estudiantes argentinos, llevad en mi nombre un saludo al poeta Carlos Guido y Spano, mi compañero de ancianidad, así 
como a vuestro Presidente Sáenz Peña, mi noble amigo, a Estanislao Zeballos, a Pastor y a Rafael Obligado, a Pedro Arata, mis constantes corresponsales, y a los literatos que hoy enaltecen con sus producciones a la gran patria de Juan María Gutiérrez, de Miguel Cané, de Hilario Ascazubi, de Faustino Sarmiento y de Bartolomé Mitre.

Jóvenes delegados de Chile y del Brasil: En vuestras patrias pasé gratas horas de mi mocedad lejana, en comunión espiritual con nuestros más grandes escritores del siglo XIX. Eusebio Lillo, Diego Barros, Benjamín Vicuña Mackena, los hermanos Amunátegui, Guillermo Matta, los Arteaga Alem, Eduardo de la Barra, Victorino Lazarria, Blest Gana, Zorobabil Rodríguez, Domingo Santa María, y una pléyade numerosa de mis contemporáneos que duermen el sueño misterioso. Como yo, solo perdura Manuel Martínez, para quien os encomiendo cordialísimo abrazo, así como para Toribio Medina, la más infatigable y discretas de las plumas que actualmente se consagran a estudios y disquisiciones históricas.

A vosotros, representantes del Brasil intelectual, cúmpleme pediros el servicio de que depositéis una hoja de laurel sobre el monumento que vuestra patria ha erigido a la memoria del poeta Gonçalves Dias, con quien me ligara, desde pocos meses antes de su fallecimiento, cordialísima amistad. Y si queréis, señores delegados, extremar vuestra benevolencia, poned en mi nombre una hoja de ciprés sobre el sepulcro de Quintino Bocaiúva, a quien traté en Río de Janeiro en 1864, hace casi medio siglo, en que corriendo los años, me favorecieron con su afectuosa correspondencia y con obsequio de libros para la Biblioteca de Lima.

Y vosotros, los delegados uruguayos, expresad a Zorrilla de San Martín, el ínclito cantor del Tabaré y mi simpático compañero en el Congreso Americanista de La Rábida, así como al egregio Enrique Rodó y a los demás poetas y escritores, mi sincero aprecio por la cultura de vuestros literatos. 
A vosotros, los delegados de la juventud estudiosa de la patria de Olmedo, cúmpleme deciros que son imperecederos mi aprecio y admiración por mis amigos personales, Juan Montalvo, Pedro Carbo, Luis Cordero y Carlos R. Tobar.

Para mis señores delegados de Bolivia, no cabe hacer distinciones entre vuestros literatos y los de mi país. Cuando hablo de Manuel Vicente Ballivián, de Claudio Pinilla, de José Carrasco, de Diez de Medina, de O'Connor D’Arlach, de Lino Romero y de otros, paréceme estar hablando de los de casa. Tened la amabilidad de comunicarles mi efusivo recuerdo.

Entre el Perú y Centro América, patria de Irizarri, hubo siempre escasez de relaciones, motivada por la situación geográfica. Os ruego, señores delegados, trasmitid mi más cariñoso recuerdo a Rubén Darío, a Batres y a Francisco Gavidia.

Para con los escritores de la patria de Andrés Bello, la heroica Venezuela, es también muy sincera mi admiración. El inspirado poeta Abigail Lozano, el genial Juan Vicente Camacho y el laborioso Arístides Rojas me favorecieron siempre con afectuos a correspondencia. $Y$ entre mis amigos del presente, cuento al notabilísimo historiador don Francisco González Ginán y al ameno crítico Gonzalo Picón Febres. Tened la amabilidad, señores delegados, de trasmitirles, así como a los escritores de la nueva generación, mi efusivo saludo.

El Paraguay vivió durante los tiempos coloniales intimamente ligado al Virreinato de Lima. El trágico fin de Antequera conmovió a ambas colectividades, y cuando aquel pueblo se independizó de España, no desaparecieron sus afinidades con nosotros. Los nombres de Manuel Domínguez, de Báez, de Silvano Mosquera, del ex Presidente Gondra y otros nos son familiares como cultivadores de las letras. Os pido señores delegados del Paraguay, que les trasmitáis mis cariñosos conceptos. 
La patria del más melodioso y delicado poeta de América, José Joaquín Palma, ha venido también a tomar participación en este grandioso certamen de las universidades republicanas. Ruego a los dignos delegados de Cuba que trasmitan mi más intenso saludo a mis amigos Rafael Montoro, Manuel Sanguiye, Bonifacio Byrne, Manuel Pichardo, Aurelio Castillo de González y Lola R. de Tió.

Recientemente incorporada en el consorcio de las naciones, la República de Panamá es ahora cuando nace a la vida literaria, por mucho que en las letras colombianas figuren con brillo nombres como el de mi amigo Arosemena. Hago votos porque el porvenir reserve para la literatura panameña una estrella de primera magnitud.

Señores del Centro Universitario del Perú: De este día fausto que me habéis obsequiado -día en que yo y mis hijos señalaremos en la memoria con la presilla más blanca de la gratitud-me llevo un álbum como testigo tangible de la nobleza de vuestras almas y el afecto vuestro que yo ambicionaba poseer, y que ha tenido la gloria de ver que no es fantástico ensueño de literato sino una realidad hermosa. El orador que, en nombre de la juventud de mi patria me ofrendó este álbum, quiere que el viejo tradicionista os bendiga y vosotros todos tenéis la mejor bendición en vuestro cerebro, nutrido de ideales y en vuestro corazón, repleto de voluntad para las buenas obras. Hago votos del más sincero fervor porque, así como sois jóvenes abiertos a todas las generaciones y grandezas, conservéis para mañana, cuando seáis hombres y ancianos, el alma joven y altiva.

Gracias, infinitas gracias mis buenos amigos. No encuentro otra forma de corresponder a vuestra cariñosa manifestación que enviar un beso sobre la frente pura de vuestras madres, de vuestras novias $y$ de vuestras hermanas, ya que mis manos temblorosas no pueden vencer la incapacidad de los años para cortar flores de mi jardín y ofrendárselas en un ramo.

He dicho. 
De la lectura de este documento sumamente valioso -y casi desconocido-queremos referirnos a los nombres más relevantes citados por Ricardo Palma. En total nombra a 63 personajes de la historia, la literatura y la política americanas. Muchos de ellos estaban ya fallecidos, y los otros eran honra de cada uno de sus países de origen. De la república Argentina cita a Carlos Guido y Spano (19/1/1827-25/7/1918), “mi compañero de ancianidad", que, como Palma, fue cultor del Romanticismo en obras como Hojas al viento (1871) y Ecos lejanos (1895). También a José María Gutiérrez (6/5/1809-26/2/1878), genuino representante del liberalismo de su época, extraordinario promotor de la cultura y autor de cuadros de costumbres, novelas, biografías, crítica literaria y trabajos científicos. A Roque Sáenz Peña (19/3/1851-9/8/1914), entonces Presidente de Argentina, lo llama "mi noble amigo". Este querido héroe de la Guerra del Pacífico estuvo al lado de Francisco Bolognesi en la inmolación de Arica. Nombra también a un grupo que el tradicionista denomina "mis constantes corresponsales". Entre ellos están: Estanislao Zeballos (27/7/1854-4/10/1923), alta figura intelectual y política de la Argentina, jurista, político, periodista, catedrático, historiador, etnógrafo, geógrafo, legislador y novelista y Pedro Narciso Arata (29/10/1849_ 5/11/1922) que a sus merecimientos como farmacéutico, químico y profesor universitario hay que agregar la pasión por los libros, que se liga con el Palma amante de "viejos infolios"; fue un bibliógrafo que llegó a reunir una colección de casi 60 mil obras. Y estará también el notable Rafael Obligado, conocido como "el poeta de Paraná", baluarte del romanticismo que escribió poesía con temática gauchesca. Así como la prosa de las Tradiciones del venerable limeño es referente de nuestra identidad, el poema de Obligado titulado "Santos Vega" es el texto lírico emblemático y el más perfecto dentro de las 
leyendas argentinas. Otro poeta gauchesco, citado en el mismo discurso de Palma, es su amigo Hilario Ascasubi (14/1/180717/10/1875) quien llevó a Palma a la casa de Lamartine,en París, y también con él visitó la tumba de Musset. Ascasubi utilizó a veces como seudónimo los nombres de dos obras suyas: "Paulino Lucero" y "Aniceto el Gallo". El tradicionista estaba, sin duda, al tanto de esa literatura regional que se afianzaba en el continente.

Al dirigirse a los delegados de Chile y del Brasil Palma hace alusión a su estadía en tierras mapochas y cariocas: "En vuestras patrias pasé gratas horas de mi mocedad lejana, en comunión espiritual con nuestros más grandes escritores del siglo XIX". De Chile cita a historiadores importantes como Benjamín Vicuña Mackena (25/8/1831-25/1/1886), acaso el más insigne que escribió variados libros relacionados con recopilaciones históricas, recolectando documentos de la historiografía chilena. Tuvo correspondencia con su par de Lima quien lo llamaba en algunas misivas "mi antiguo y buen amigo", aunque por la época de la Guerra del Pacífico estas dos figuras representativas se enfrascaron en algunas polémicas, cada quien velando por el interés de sus respectivos países. Otro de los nombres ilustres que aparece en el discurso de Palma es Diego Barros Arana (16/8/1830-7/1 1/1907) autor de la Historia General de Chile que relata toda la biografía vital del país mapocho desde la prehistoria hasta 1830, en 16 tomos. Respecto al bibliógrafo e historiador José Toribio Medina (21/10/1852-1/12/1930) dirá que es la "más infatigable y discreta de las plumas que actualmente se consagran a estudios y disquisiciones históricas". En efecto, Medina resulta el mayor recolector de fuentes para el estudio de la historia de su país; entre sus obras destacan la Colección de historiadores de Chile y los Documentos inéditos para la historia de Chile; en 1887 publicó Historia de la Inquisición de Lima en donde sigue los pasos del 
estudio palmista titulado Anales de la Inquisición de Lima. Junto con estas figuras aparecen otros nombres importantes del país del sur con los cuales Palma tuvo vínculos personales, "en comunión espiritual”: los hermanos Amunátegui (Miguel Luis y Gregorio Víctor); Eusebio Lillo, Guillermo Matta, Eduardo de la Barra, Victorino Lazarria, Blest Gana, Zorobabil Rodríguez, Domingo Santa María y Manuel Martínez.

Cuando menciona a los representantes del Brasil, Palma evoca con emoción dos nombres preclaros cuyos recuerdos van acompañados de nobles afectos. Uno de ellos es el notable Antonio Gonçalves Dias (10/8/1823-3/1 1/1864) encuadrado en el Romanticismo, cuya obra logró crear un sentimiento nacionalista al incorporar asuntos relacionados con los pueblos y con los paisajes brasileños. Al igual que José de Alencar, desarrolló el Indianismo. Poco antes de la muerte del brasileño, en 1984, Palma lo llegaría a conocer en París donde supieron intimar al calor de la predilección por el poeta Enrique Heine. Y al lado de Gonçalves Dias, estará otro brasileño que fue periodista, escritor y político: Quintino Bocaiúva (4/12/183611/6/1912) "a quien traté en Río de Janeiro en 1864," hace casi medio siglo, en que corriendo los años me favorecieron con su afectuosa correspondencia y con obsequio de libros para la Biblioteca de Lima". Conocido por su participación en el proceso de Proclamación de la República del Brasil, adoptó el seudónimo de Bocaiúva (nombre común de dos especies nativas de palmeras), para afirmar su nativismo. Como político fue el Primer Ministro de Relaciones Exteriores de Brasil, entre 1889 y 1891 y Presidente del Estado de Río de Janeiro, entre 1900 y 1903. Por su destacable rol en el fomento de la prensa en su país,

11 En ese año el Presidente San Román nombró Cónsul del Perú en Belem do Pará a Ricardo Palma, aunque las últimas investigaciones -especialmente de Oswaldo Holguín- han corroborado que arribó al Brasil después de viajar a Europa pero no ejerció el cargo. 
fue señalado por sus contemporáneos como "el príncipe de los periodistas brasileños". Muerto pocos días antes del discurso de Palma, ofrecido en julio de 1912, el tradicionista les diría a los representantes del Brasil: "si queréis, señores delegados, extremar vuestra benevolencia, poned en mi nombre una hoja de ciprés sobre el sepulcro de Quintino Bocaiúva, a quien traté en Río de Janeiro en 1864, hace casi medio siglo".

De la república del Uruguay Palma hace el recuerdo de dos notables figuras: el escritor Juan Zorrilla de San Martín, "ínclito cantor del Tabaré" y del ensayo histórico sobre la figura del prócer (José) Gervasco Artigas titulado La epopeya de Artigas (1910). Ambos coincidieron en el Congreso Americanista en España de 1892 con motivo de los cuatrocientos años del viaje de Colón a América. La otra figura nombrada por Palma es el "egregio José Enrique Rodó" (15/7/1871-1/5/1917) cuyos ensayos, marcados por el americanismo y la crítica a la cultura norteamericana, tuvieron una extraordinaria difusión en el continente en obras como Ariel, Motivos de Proteo y El mirador de Próspero.

$\mathrm{Al}$ referirse a sus amigos de la "patria de Olmedo" nombra a Juan Montalvo (13/4/1832-17/1/1889), el notable ensayista de Siete tratados (1882) y Geometría moral (póstumo, 1902), cuyo pensamiento liberal estaba plenamente marcado por el anticlericismo y la oposición a los dictadores de su país, como Gabriel García Moreno e Ignacio de Veintemilla. Palma también nombra a otros "amigos personales" como Pedro Carbo (19/3/1813-24/12/1894) político y diplomático que se asentaría, en algunas etapas de su vida, en el Perú; Luis Cordero Crespo (6/4/1833-9/7/1912) prominente político quien llegó a ocupar la presidencia del Ecuador en dos períodos (el primero en 1883 y el segundo de 1892 a 1895). En agosto de 1875 estuvo en Lima y es probable que de esa época data su amistad con el tradicionista. 
Al hablar de Bolivia Palma acentúa la ligazón espiritual que vincula a nuestro país con la república del Altiplano. Dice: "no cabe hacer distinciones entre vuestros literatos y los de mi país (...) paréceme estar hablando de los de casa”. Evoca las figuras de Manuel Vicente Ballivián (Arequipa, 1848-La Paz, 1921), historiador y político, fue director de la Biblioteca Boliviana de Geografía e Historia (1887-1894); Claudio Pinilla Vargas (La Paz, 1857-1928), poeta, dramaturgo y diplomático. Participó en la Guerra del Pacífico. Como poeta nunca perdió el culto al romanticismo que lo marcaría desde su juventud. Cumplió funciones diplomáticas en nuestro país, en Paraguay, Chile y Brasil. José Carrasco Torrico (Cochabamba, 4/1 1/1863-La Paz, 24/5/1921). Usó el pseudónimo “Brissot”. Fue político, escritor y periodista; alcanzó a ser Ministro de Gobierno y Justicia y Vicepresidente de la República. Tomás O’Connor D'Arlach (Tarija, 7/3/1853-9/12/1932) fue historiador, poeta y tradicionista; cronista del anecdotario del presidente Mariano Melgarejo y autor de Juana Sánchez, biografía de la heroína del tirano Melgarejo. Junto a estos personajes Palma también nombra al poeta, ensayista, político y diplomático Diez de Medina y a Lino Romero, quien formara parte de un equipo de juristas que debatió la legitimidad de Bolivia en territorios en disputa con Paraguay.

Palma, al señalar a los escritores de Centroamérica recuerda con cariño la visita que Rubén Darío (18/1/1867-6/2/1916) le hiciera en la Biblioteca. Recordemos que el poeta nicaragüense, poeta estandarte del Modernismo y genial autor de Cantos de Vida y Esperanza, hace alusión, en la conocida crónica titulada "Fotograbado", a la modernidad del pensamiento de Palma y, por vez primera, estampa allí el rótulo del movimiento que se extendió por toda América. "Él -dirá- es decidido afiliado a la corrección clásica, y respeta a la Academia. Pero comprende y admira el espíritu nuevo que hoy anima a un pequeño, 
pero triunfante y soberbio, grupo de escritores y poetas de la América española, el Modernismo". ${ }^{12}$ También Ricardo Palma cita al entonces joven poeta salvadoreño Francisco Gavidia (29/12/1863-22/10/1955) cuya obra alcanzó con el tiempo dimensiones enciclopédicas pues fue escritor, educador, historiador, politólogo, traductor y periodista. Sus biógrafos señalan que se le conoce por ser el orientador de Rubén Darío para adaptar el verso alejandrino a la métrica castellana.

Por el lado venezolano, Palma rememora con emoción a Juan Vicente Camacho (8/7/1829-4/8/1872) "uno de los bohemios" de la generación romántica que en 1853 viajó al Perú como Secretario de la Legación de Venezuela. En la capital peruana fundó, junto con Hilarión Nadal, el periódico "El Heraldo". En 1857 fue ascendido a Cónsul de Venezuela en Lima. También el tradicionista nombra al escritor e historiador Arístides Rojas (5/10/1826-4/3/1894) quien entregó magníficas contribuciones sobre la historia de su país, como Orígenes de la revolución venezolana y Orígenes venezolanos; a Francisco González Guinán (3/10/1841-7/12/1932), uno de los historiadores más destacados del siglo XIX de la patria de Bolívar quien en la ruta de Palma publicaría, en 1927,Tradiciones de mi pueblo; al escritor y diplomático Gonzalo Picón Febres autor, en 1906, de La literatura venezolana en el siglo XIX, obra de referencia para cualquier estudio sobre la literatura del ochocientos.

Recordar los estrechos lazos entre nuestros pueblos fue siempre característica muy acentuada en el autor de las Tradiciones, tal como se corrobora en el discurso que estamos analizando. Cuando se refiere al Paraguay dirá, por ejemplo, "vivió durante los tiempos coloniales íntimamente ligado al Virreinato de Lima. El trágico fin de Antequera conmovió a ambas colectividades, y cuando aquel pueblo se independizó de España, no

12 Tradiciones Peruanas, Tomo III, p. VII. 
desaparecieron sus afinidades con nosotros". Destaca luego el nombre de Silvano Mosqueira ( 1 1/9/1875-15/8/1954) autor de ensayos y semblanzas sobre personalidades históricas y hechos memorables de su país. Fue cronista de bellas evocaciones que aparecen con intensidad en libros como el conocido Semblanzas paraguayas. También nombra a Manuel Gondra, figura de gran importancia política en la historia del Paraguay: fue lingüista, historiador y ensayista, y además, Presidente de la República en dos períodos, 1910-1911 y 1920-1921.

En su repaso por los países centroamericanos Palma continúa con Cuba: "la patria del más melodioso y delicado poeta de América, José Joaquín Palma. Evoca allí a Lola Rodríguez de Tió (14/9/1843-10/1 1/1924), aunque hay que precisar que esta poetisa, periodista y revolucionaria fue una portorriqueña que peleó por la independencia cubana, estableciéndose durante varias etapas de su vida en el país de Martí. También aparecen nombrados el político, historiador y crítico literario, fundador del Partido Liberal, Rafael Montoro Valdez (24/10/185214/8/1933); el abogado, periodista y combatiente de la Guerra de los Diez Años Manuel Antonio Sanguily Garrite; el poeta e intérprete de los entusiasmos y agonías de un pueblo en lucha por su independencia de la corona española: Bonifacio Byrne (3/3/1860-5/7/1936). Este recuento finaliza con la república de Panamá donde el tradicionista destaca la figura cimera de Justo Arosemena (9/8/1817-23/2/1896) enciclopedista por la multiplicidad de sus conocimientos: fue jurista, estadista, escritor, político, profesor, orador, economista, historiador, etc. Muchos lo sindicaron como "el panameño más relevante del siglo XIX". 


\section{Conclusiones}

De lo expuesto en este trabajo podemos concluir lo siguiente:

- El discurso leído revela la profunda sintonía amical que Palma mantenía con personalidades de diferentes latitudes demostrada en el copioso epistolario y en el "obsequio de libros para la Biblioteca de Lima". Esta gran capacidad de relacionarse con la cultura de todos los pueblos americanos puso de relieve las afinidades y divergencias con diferentes escritores, artistas, políticos, historiadores e intelectuales, especialmente del siglo XIX.

- Esta relación continental demuestra que Palma no era solo un escritor para limeños como lo tildaban algunos estudiosos. Él se proyectaba al mundo. Junto con su arraigo peruanista tenía una visión cosmopolita, universal.

- El género epistolar alcanzó con Palma un nivel muy alto. A través de esta vía la pluma versátil del tradicionista se erigía como un radar que captaba y tomaba el pulso a los acontecimientos nacionales e internacionales.

- Esta forma de comunicación epistolar explica como Palma escribía sus tradiciones: recababa información, recibía colaboraciones, anécdotas, datos curiosos de sus corresponsales, tanto del interior del país como de otros lugares de América.

- Demuestra sin ambages el gran aprecio, respeto y solidaridad de los jóvenes del Perú y de América -con claras muestras de desagravio- por el ilustre tradicionista. La animadversión provenía, sin duda, de la prédica de González Prada, mas no de la apreciación juvenil de entonces. 
- Se constata la clara intención del autor de Horas de Lucha de desacreditar los altos merecimientos de Palma, como literato y como bibliotecario. El libelo entregado a los asistentes al Congreso es lamentable y se vuelca en contra del propio remitente.

- La enemistad entre estas dos figuras de la literatura nacional está ligada al trasfondo político y social de finales del siglo XIX y principios del XX. Tal vez González Prada resulte menos culpable que la heteróclita clase política, la cual, obedeciendo a coyunturas de época, tomó como punto de referencia las divergencias ideológicas existentes, -aunque exageradas-, entre los dos grandes representantes de nuestra literatura.

\section{Bibliografía}

BATTICUORE, Graciela Juana Manuela. Gorriti Cincuenta y tres cartas inéditas a Ricardo Palma. Lima, Universidad de San Martín de Porres, Lima, 2004.

HOLGUín Callo, Oswaldo. Tiempos de Infancia y Bohemia. Ricardo Palma (1833-1860). Lima, Fondo Editorial de la Pontificia Universidad Católica del Perú, 1994.

Páginas sobre Ricardo Palma. Lima, Editorial Universitaria de la Universidad Ricardo Palma, 2001.

MILLA, Rodolfo. Oquendo, Tomo I. Lima, Hipocampo Editores, 2006.

MOREANO, Cecilia. Relaciones literarias entre España y el Perú: la obra de Ricardo Palma. Lima, Editorial Universitaria de la Universidad Ricardo Palma, 2004.

PALMA, Ricardo. Tradiciones Peruanas. Edición de Carlos Villanes Cairo, Madrid, Ediciones Cátedra, 2006 (3ª Ed.).

Tradiciones Peruanas, Tomo III. Lima, Editorial Cultura Antártica, 1951.

Epistolario General (1846-1891). Lima, Editorial Universitaria de la Universidad Ricardo Palma, 2005. 
PANTIGOSO, Manuel. Terra Brasilis. Lima, Editorial Nido de Cuervos, 2012.

Estuardo Núñez y la Generación de la Crisis, Tomo II. Lima, Editorial Hozlo, 2010.

SÁNCHEZ, Luis Alberto. La literatura peruana, Tomo IV. Lima, Editorial Imprenta Desa, Banco Central de Reserva del Perú, 1989 (6 $6^{\text {a Ed.). }}$

Manuel Gonzáles Prada Obras, Tomo II. Lima, Ediciones Copé, 1986.

TAURO del Pino, Alberto. Enciclopedia ilustrada del Perú, Tomo 12. Lima, Editorial Peisa, 2001 ( $3^{\circ}$ Ed.).

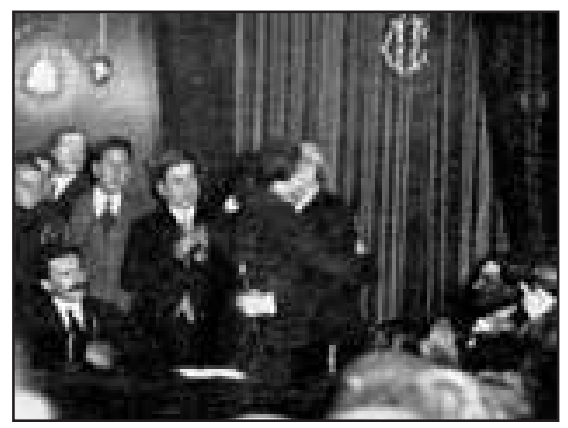

El señor Ricardo Palma abraza al Presidente del Centro Universitario, después de escuchar el cariñoso discurso que éste pronunciara.

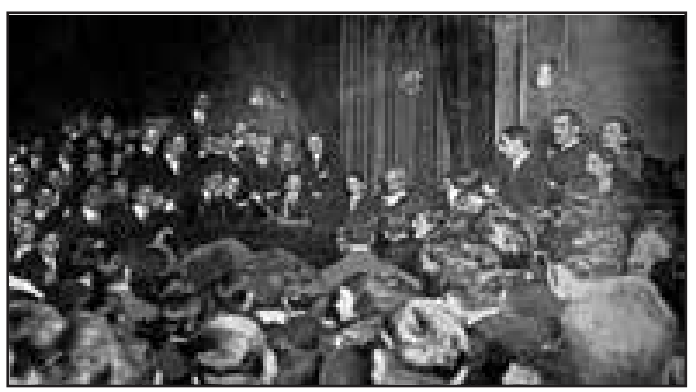

El tradicionalista leyendo su discurso de agradecimiento.

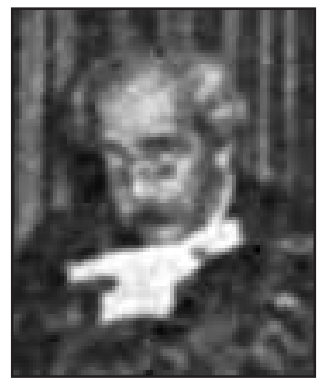

Don Ricardo Palma 